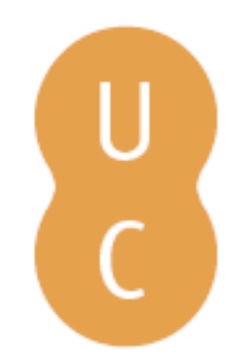

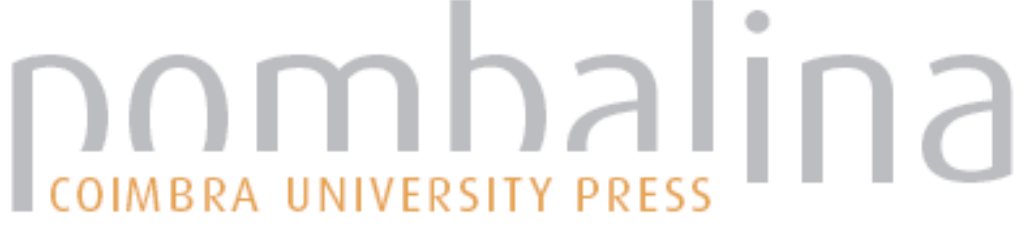

\section{Fraude académica discente e contexto moral}

Autor(es): $\quad$ Thiry-Cherques, Hermano

Publicado por: Imprensa da Universidade de Coimbra

URL

persistente:

URI:http://hdl.handle.net/10316.2/38809

DOI:

DOI:http://dx.doi.org/10.14195/978-989-26-1123-5_5

Accessed : $\quad$ 26-Apr-2023 02:10:55

A navegação consulta e descarregamento dos títulos inseridos nas Bibliotecas Digitais UC Digitalis, UC Pombalina e UC Impactum, pressupõem a aceitação plena e sem reservas dos Termos e Condições de Uso destas Bibliotecas Digitais, disponíveis em https://digitalis.uc.pt/pt-pt/termos.

Conforme exposto nos referidos Termos e Condições de Uso, o descarregamento de títulos de acesso restrito requer uma licença válida de autorização devendo o utilizador aceder ao(s) documento(s) a partir de um endereço de IP da instituição detentora da supramencionada licença.

Ao utilizador é apenas permitido o descarregamento para uso pessoal, pelo que o emprego do(s) título(s) descarregado(s) para outro fim, designadamente comercial, carece de autorização do respetivo autor ou editor da obra.

Na medida em que todas as obras da UC Digitalis se encontram protegidas pelo Código do Direito de Autor e Direitos Conexos e demais legislação aplicável, toda a cópia, parcial ou total, deste documento, nos casos em que é legalmente admitida, deverá conter ou fazer-se acompanhar por este aviso. 


\section{5 \\ FRAUDE ACADÉMICA DISCENTE E CONTEXTO MORAL}

Hermano Thiry-Cherques

Fundação Getúlio Vargas

bttp://dx.doi.org/10.14195/978-989-26-1123-5_5 
(Página deixada propositadamente em branco.) 


\subsection{Introdução}

Dentre as transgressões éticas menores, o ato de fraudar (lat. fraudatis ) ou de frustrar pessoas e descumprir deveres morais é tematizado em três instâncias: a tipificação do agir fraudulento; a contextualização do agente fraudador, no caso os estudantes universitários; e a entidade fraudada, pessoa, grupos ou instituição, no caso a academia como preposta da ciência.

Enquanto ação transitiva a fraude académica discente envolve ${ }^{19}$ : uma postulação da parte do fraudador que tem uma implicação falsa; o acreditar por parte da instituição académica fraudada no que julga ser verdade e efetuar ações baseadas nessa suposição; a implicação de danos da ação fraudulenta para a ciência e para a sociedade.

As formas de coibir a fraude académica discente tendem à intimidação e ao ultimato num extremo e à complacência tolerante no outro. Neste ensaio trago à discussão a possibilidade de diminuir a sua frequência e intensidade mediante o cancelamento ou atenuação das suas causas, dos móbeis que a induzem.

A fraude é o género, a académica a espécie, o discente o caso. Procurarei estabelecer um vínculo entre estas três esferas. Na primeira parte do texto exponho o que julgo ser comum às diversas correntes do pensamento ético contemporâneo. Em seguida apresento a definição dos casos mais frequentes de fraude em face do conceito basilar de academia. Na segunda parte discuto os indutores condicionantes

19 Ver resumo de David G. Mills (2003). 
das fraudes discentes. Concluo com uma sugestão sobre a forma de atenuar os seus efeitos e de diminuir a sua ocorrência.

\subsection{A ética}

Inicio com um resumo do que penso ser o consenso sobre as questões éticas nos dias que correm. Procederei por clivagem simples, partindo do ponto mais abstrato, que vem a ser a visão que a filosofia entende sobre o ser humano. Esta é uma síntese pessoal, daí a não citação de fontes, autores e correntes de pensamento.

A ciência moral da atualidade segmenta o ponto de vista das escolas filosóficas em duas vertentes. Uma, mais tradicional, vê o ser humano como um indivíduo situado em uma totalidade, em um corpo social uno. Outra, posterior à virada do século xx, vê o ser humano como pessoa situada espaço-temporalmente em uma associação mutante e de perfil irregular. O ponto de vista mais tradicional, que entende o ser moral como indivíduo particular, como o ente limite da divisão de uma totalidade, é hoje minoritário se comparado ao entendimento do ser moral como pessoa singular, o ente primário de uma sociedade. Desta evolução ou preferência resultam duas implicações: a pouca serventia hoje atribuída ao discurso sobre a conduta do ser humano em abstrato, isto é, sobre a ética normativa; e a utilidade atribuída à busca do entendimento da moralidade em termos de entes psíquicos imersos em uma cultura, isto é, em termos da eticidade das pessoas reais em sociedades e períodos estipulados.

Seguindo-se esta forma de ver, que é maioritária, mas não é exclusiva, tem-se que a definição que adotamos sobre o que vem a ser uma pessoa - o ser humano na sua integridade biológica e intelectual - é a chave para discorrer sobre os fundamentos da moralidade. A reflexão filosófica atual, incitada pelos avanços das ciências particulares, notadamente os das ciências psi e os das neurociências, veio 
maioritariamente a considerar como atributos essenciais da pessoa, além da faculdade do juízo racional, a autoconsciência e as faculdades de simbolizar e de comunicar. Este consenso ou quase consenso instrumentalizou a filosofia para equacionar problemas como os do aborto (o feto é uma pessoa?), o da eutanásia (uma pessoa tem o direito e capacidade de escolher a própria morte?) e assim por diante.

A análise do fenómeno da fraude académica, a que procedo neste texto, encara-a sob a ótica da reflexão ética contemporânea; isto é, não focada no aluno abstrato, universal, mas em entes racionais particulares dotados de autoconsciência e da capacidade de ação simbólica, ou, mais simplesmente, do domínio dos atos de fala. Em outros termos, a análise considera o fraudador, a fraude e o fraudado como entes situados, contextualizados.

A verificação que procedo na apreciação da fraude académica é, pois, situada espaço-temporalmente, posicionada em uma cultura dada. De novo aqui existem duas abordagens distintas. A mais clássica situa a pessoa moral em uma totalidade natural ou criada, a natura naturata, constante e imutável em sua essência. A mais contemporânea situa-a em um meio fluido e mutável, entendendo-se cultura como o conjunto de bens e valores dados em um espaço-tempo que construímos e reconstruímos e que nos condiciona. $\mathrm{Na}$ perspetiva mais tradicional temos o ethos, o caráter, a forma de ser constituída. Na perspetiva que adoto temos o ethos como a conduta, constituindo a cultura ou maneira de existir e sendo constituída por esta mesma cultura, por esta mesma maneira de existir determinada.

Para entender o espaço-tempo moral com que lidamos devemos proceder a uma terceira clivagem, não mais excludente, mas agora seletiva das caraterísticas e problemas dominantes do meio universitário ocidental do nosso tempo. Um meio sabidamente complexo e controverso, mas mediado por três dentre inúmeras questões e problemas da atualidade: a liberdade, a individualização e a racionalização. 
A inconstância da vida social e a questão da liberdade - eterna querela entre o livre e o servo arbítrio - são as marcas mais profundas da contemporaneidade. Como sustentar qualquer posição que seja em um mundo que reconhecemos em evidente reconstrução? Basta vermos as mutações na forma e na apreciação do erótico para constatarmos que qualquer perspetiva que possamos ter sobre o corpo, sua prática e sua imagem caducará em pouco tempo. No que se refere à mente, como sustentar que somos livres para escolher depois da psicanálise, do advento do marketing e dos avanços das ciências da mente? Por outro lado, dir-se-ia o mesmo da liberdade depois da democratização não só política, mas dos costumes e, principalmente, do livre acesso às informações? Discutir a fraude implica inquirir sobre até que ponto alguém é livre para copiar, para tomar emprestadas ideias, para se promover a si e aos amigos, para fabular e falsear, etc. Estas dúvidas sobre a liberdade conduzem a outras, entroncadas no problema da individualização.

A individualização moral se coloca sob ângulos: o da autodeterminação e o da autonomia. A autodeterminação refere à aspiração, que data dos gregos, da autarkeia, do bastar-se a si próprio, da liberação das inquietações do corpo, da mente e das convenções sociais, excluída a integração na polis; isto é, excluído o isolamento social. A autonomia se refere à busca da liberdade individual, do autogoverno. É expressa cruamente no preceito moral pragmático: "eu tenho o meu interesse, você o seu: mostre-me que o seu interesse é do meu interesse e eu me ocuparei dele". A dúvida que emana das duas formas do individualismo moral é de limite: em que ponto a autarkeia e a autonomia lidam com o egocentrismo e com o insulamento cultural? Esta dificuldade em precisar um limite que não seja puramente normativo nos leva a inquirir sobre a fronteira de determinação (os términos) e da lógica (a razão de) da fraude académica.

A racionalização em termos da ética é a redução do humano a uma ideologia, a edificação de uma lógica sobre uma ideia não fundamentada. Seja esta ideia a da naturalização do mercado, ou a do 
bem comum, ou da solidariedade, ou a do bem estar, o que sustenta uma ideologia é, por definição, uma ideia matriz, uma representação mental abstrata e, muitas vezes, quimérica. Toda a racionalização estabelece um paradigma. Pois o paradigma hoje em voga na esfera académica é o da aferição numérica, a da subordinação de tudo à ideia reducionista de que o não mensurável é especulativo e, por isto, deve ser transposto ou abandonado. A dúvida que aqui se nos apresenta na apreciação da fraude é a de como medir não a conduta humana, mas a sua causalidade e a sua intencionalidade. Em que pesem todas as estatísticas que possamos estabelecer, do ponto de vista moral pouco ou nada importa saber quantos fraudadores há e quantas infrações foram cometidas. O que importa discutir é quem fraudou a quem e por que razão, questões irredutíveis a índices. Não existe uma entidade como a fraude 3,2t, onde t é o índice diferido de transgressão moral.

\subsection{As fraudes académicas}

A primeira esfera de entendimento da fraude académica discente é, ou melhor, são os diversos tipos de fraudes no contexto analisado. Na relação que se segue, arbitrei denominações genéricas para fraudes de mesmo tipo. Inicio com as mais frequentes, relacionadas à cópia ou reprodução. Seguem-se as de pilhagem, as dirigidas a promover sem mérito, as de conteúdo e as que falseiam os resultados do esforço de investigação. A listagem é longa. Baliza a argumentação final, mas é prescindível para a sua compreensão.

\subsubsection{Fraudes de reprodução}

O plágio é certamente a mais frequente das fraudes académicas. $\mathrm{Na}$ sua forma direta, consiste em copiar uma fonte, muitas vezes o 
trabalho de um colega (a "cola", no dizer brasileiro), sub-repticiamente, sem que a fonte ou instância fraudada - a instituição ou a ciência em abstrato - tenham conhecimento. As diversas formas de plágio apresentam dois traços relevantes para a devida apreciação moral. A primeira é a sua característica atenuante, que o diferencia do roubo e do furto, já que a fonte permanece intocada e na posse de quem detinha originalmente o original copiado. A segunda é a da sua ambiguidade. Nem sempre o plágio foi ou é julgado negativamente. O King Lear de Shakespeare é uma cópia de trechos inteiros reproduzidos verbatin do anónimo King Leir.

$\mathrm{Na}$ forma do centão ou da rapsódia, o plágio consiste em copiar trechos de diversas fontes compondo-as em um texto "único". Na forma paráfrase, consiste em escrever a mesma coisa que uma fonte, mas de maneira diversa. Na forma autoplágio, consiste em reapresentar textos e pesquisas com roupagem diversa da original, ou das anteriores, em vários casos. Nenhuma destas formas é reprovável em termos absolutos. O plágio centão é usual na poesia e na música. Um centão é um conglomerado em que o escritor reordena versos de outro ou de outros poetas para criar um poema inteiramente novo. Já foi muito popular. Antônio compôs uma versão em forma de epitalâmio (hino nupcial), com versos de Virgílio, para celebrar as bodas de Valentiniano. O que tornava reprovável os centões e as paráfrases era o serem compostos principalmente de poemas indecorosos. Fora das artes, o centão e a paráfrase são, desde sempre, estratégias de aprendizagem dos trabalhos escolares, o que induz a que hoje, graças ao Google e a Wikipédia, os discentes, treinados desde a infância, estejam aptos a compor alegremente relatórios e textos diversos. A fraude académica aqui não está na composição, mas no não reconhecimento das fontes. Já o autoplágio pode ser considerado como instrumento de aperfeiçoamento e de progresso. A Investigação sobre o entendimento bumano, de David Hume, é uma reescritura do Tratado da natureza humana, que ele considerava uma obra juvenil. 


\subsubsection{Fraudes de pilhagem}

O esbulho, a apropriação de títulos e ideias de outros, embora eticamente insustentável, curiosamente não recebe a mesma atenção legal do plágio. Na maioria dos países não existe copyright para conceitos que não foram legalmente registrados. A ideia de Guerra e Paz é de Petrarca (Pace non trovo e non ho da far guerra...), não de Tolstoi. Dan Brown fez rios de dinheiro copiando o tema de dois autores ingleses de pouco êxito. Processado, venceu tranquilamente a causa. Publicações anónimas ou sob pseudónimo podem ser legalmente copiadas e títulos não estão protegidos. Se der a este texto o título de Código da Vinci ou O capital, não serei incomodado.

As fraudes de pilhagem incluem ainda a falsa adição e a deturpação. A falsa adição, caracterizada pela continuação ou complementação sem conhecimento do autor ou do recetor de um texto, é prática antiga, como prova o incompetente terceiro tomo do Quixote. A deturpação, desvirtuamento, distorção ou a deformação do discurso, fazendo o autor dizer o que não disse, se tornou comum em textos digitais, que podem ser alterados e redistribuídos facilmente. Não é uma prática nova. O que se afirma no texto bíblico é ser mais fácil uma corda - e não um camelo - passar pelo fundo de uma agulha. Uma fraude milenar de tradução, que ninguém se ocupa em corrigir.

\subsubsection{Fraudes promocionais}

As mais comuns das fraudes promocionais são a burla das citações cruzadas de grupelhos discentes e docentes que se citam mutuamente a fim de aumentar os respetivos índices, e o compadrio, o conluio, a mancomunação entre discentes e docentes, 
que vai desde o fenómeno conhecido como "banca amiga" até à glorificação de trabalhos torpes e pesquisas não fundamentadas. Junto à autopromoção, a ação de alabar, do lat. alapo, soprar, no caso soprar a própria vela, se tornara tão comum que é julgada moralmente aceitável.

\subsubsection{Fraudes de conteúdo}

As fraudes de conteúdo são as menos visíveis, e, em termos da episteme, as mais graves. Compreendem o recurso ininteligibilidade, o ressuscitamento de textos e uma série de falácias.

O texto ininteligível é, de regra, assente sobre cálculos que poucos dominam, como o cálculo vetorial, ou de termos que parecem precisos, mas cuja significação não se liga aos referentes examinados. É uma fraude tornada célebre pelo físico Alan Sokal, da Universidade de New York. Indignado com a complexidade e a forma tortuosa, às vezes ininteligível em que as ideias de Deleuze e de Guattari são expostas, Sokal escreveu um artigo, intitulado "Transgredindo fronteiras: para uma hermenêutica transformadora da gravidade quântica" que foi publicado pela prestigiosa Social Text(Sokal, 1996). Em que pese a seriedade da revista, tratava-se de uma paródia, polvilhada de absurdos, entre eles a sugestão que o valor da constante $\pi$ muda segundo as atitudes da época. A brincadeira demonstrou como parte da reflexão pós-moderna tem mais valor estético do que lógico. Como autores das ciências humanas e sociais do pós-guerra a esta parte fazem uso de conceitos que não compreendem, como /infinito/, /função/ e /catálise/, elegantemente encadeados para se parecerem com teorias profundas.

O ressuscitamento de textos é uma das práticas mais difundidas. Consiste basicamente em tomar um mesmo tema, dados, método e desenvolvimento para apresentar conclusões ligeiramente distintas 
em vários textos. O truque está na conversão de título, de terminologia e do estilo de redação dos textos.

Dentre as falácias, os recursos ao raciocínio verosímil, porém inverídico, o mais comum no meio académico é o do tipo ignoratio elenchi. A premissa do argumento é verdadeira, mas não é prova para conclusão. Por exemplo, nunca foi provado que do facto de enfermos com atitudes positivas ante a vida se sintam melhor, decorra que o bom ânimo contribua para a cura. A segunda falácia é a do falso dilema. No falso dilema, a alternativa /ou/ é entendida como incondicional. Como em /ame-o ou deixe-o/ ou em /quem não está a favor, está contra/. O dilema é falso sempre que existe uma terceira possibilidade, seja a neutralidade, seja a indiferença, seja, enfim, outra posição diversa das postuladas. A terceira falácia em que incorrem os trabalhos discentes é a do argumentum ad ignorantiam. Funda-se na ideia de que não existindo provas para sustentar uma posição, a posição é falsa. O argumento consiste em sustentar que não há alternativa às "verdades", e normas vigentes. É o mesmo que afirmar que uma vez que não é possível provar a inexistência das sereias, elas devem existir. A quarta e última falácia que citarei é a do primeiro modo das falácias causais, a post boc [post hoc ergo propter hoc, ou "depois disso donde devido a isso" - ou seja, sustentar que como $B$ sucede a $A, A$ é a causa de $B$ ]. A falácia consiste em considerar que uma singularidade, como a relação entre a renda do capital e do emprego tem permanecido constante, então ele é permanente. No ano que terminou, os dados da OCDE mostram que a constante não se sustenta, que, na verdade, é variável. Deixou uma legião de economistas perplexos, mas silentes. A falácia post hoc está por trás do raciocínio que leva a concluir que uma vez que todo banqueiro usa gravata se usarmos gravata seremos todos ricos. O engano aqui reside em que, as oscilações dos ganhos de capital e do trabalho, como a gravata e o dinheiro, são efeitos. Ambos ocorrem, mas um não é a causa do outro. 


\subsubsection{Fraudes de produto}

As fraudes de geração das pesquisas académicas tanto discentes como docentes, compreendem a fabulação, o falseamento, a contrafação e a formatação.

A fabulação, a invenção pura e simples de dados é a mais grosseira destas fraudes. Especialmente frequente em experimentos nas ciências humanas e sociais, decorre da impossibilidade de se replicar a situação espaço-temporal em que os dados foram coletados e da dificuldade em se garantir que os respondentes recordem as informações prestadas passados meses da data do experimento.

O falseamento ou deturpação de dados primários, ou sua simples invenção está muitas vezes baseada na multiplicação engenhosa. Consiste em multiplicar os resultados de uma pequena amostra por um número arbitrário. Quando bem feita, é difícil de ser identificada, já que o levantamento de facto foi feito e as informações efetivamente coletadas e sistematizadas.

A contrafação tem uma história venerável. Os mais antigos contrafatores que se têm notícia foram os evangelistas, apócrifos ou não, que copiaram a São Marcos, que, aliás, parece ter também copiado fragmentos de textos anteriores, como os encontrados nas cavernas do Mar Morto. Menos venerável, a falsa autoria, uma contrafação comum na literatura, comprovadamente utilizada por autores da estatura de um Alexandre Dumas, invadiu a academia. Na sua vertente atenuada consiste na contratação de assistentes ghost-writers. Na vertente mediana, na aquisição de pesquisas e textos prontos, incluindo-se dissertações e teses, hoje vendidas online a preços módicos. Na sua vertente mais deplorável, a contrafação da falsa autoria consiste na servidão imposta aos discentes que devem pensar e escrever segundo e para o seu feitor, uma abominação clara e abertamente incentivada pela academia e pelos órgãos oficiais de financiamento. 
A formatação, fraude que data dos monges medievais, que cristianizaram tudo o que podiam, é a forma ancestral do sistema de editoração: a harmonização ou redação de textos focadas nas exigências do mercado editorial. Prática que tornou possível que pessoas incultas e intelectualmente vazias, celebridades, bufões e magos, muito ignorantes ou muito ocupados para escreverem qualquer coisa, viessem a publicar desde best-sellers a textos científicos. Transposta para a academia, a editoração é oferecida graciosamente até por editoras de revistas científicas, que, claro, fazem da discrição o seu ponto de honra.

\subsubsection{Fraudes de generalização}

Por último, temos as fraudes decorrentes da vulnerabilidade da epistemologia da moda. As fraudes de generalização, que compreendem a estatística criativa e a generalização confirmativa.

A falcatrua representada pela estatística criativa mais grosseira consiste em estender o domínio dos resultados dos cálculos para além do que permite efetivamente a amostra. Deriva da consabida dificuldade de sustentar logicamente a generalização probabilística de caráter indutivo. O probabilismo é, em essência, generalizante. É dado a produzir uma gama infindável de generalizações a partir de associações parciais e imperfeitas entre variáveis (classe social e empregabilidade; lucro e sustentabilidade; produtividade e treinamento). Os discentes exploram o probabilismo em várias das suas fragilidades: 1) a da impossibilidade de controlar a interatuação dos fatores (as associações causais podem ser mera coincidência. Bertrand Russel gostava de citar a implicação do apito da fábrica de Manchester com o cotidiano de Cambridge); 2) a da impossibilidade de descrever o real de forma probabilística (a probabilidade de as pedras voarem em Marte, embora mínima, existe); 3) a do condicionamento na eleição 
das variáveis (trabalham exclusivamente com dados pré-existentes); 4) a variação espaço-temporal das condições no mundo social (o que foi facto nos anos 2000, não necessariamente o é hoje); 5) a multiplicidade de se aventar um número indefinido de explicações (teorias) que apreendam um mesmo fenómeno; 6) as associações, que deixam de lado exceções e particularidades; e 7) o facto de que o objeto observado pode ser uma singularidade.

A generalização confirmativa é similar à explicação estatística: estabelece uma relação não dedutiva entre premissas explicativas e uma conclusão. Por exemplo, se todo objeto que examinamos tem a propriedade $P$, e tem, igualmente, a propriedade $Q$, sustentar que todo e qualquer objeto que tem a propriedade $P$ tenha a propriedade $Q$. A inferência, no caso, é plausível, mas não é universalizável. Serve como suporte indutivo. $\mathrm{O}$ que distingue a generalização confirmativa da explicação causal e da explicação estatística é que a causal explica inteiramente porque o fenómeno explanandum se produziu, a estatística explica parcialmente (probabilisticamente) e a generalização confirmativa não o explica de forma alguma.

\subsection{A Academia}

Relacionadas as fraudes, passo agora à segunda esfera em questão: a academia.

As instituições de ensino superior, a corporação dos estudantes e dos docentes e as sociedades com caráter literário, científico ou artístico, hoje denominadas de academia, têm origem conceitual na escola fundada por Platão nas cercanias do jardim dedicado ao herói Academos.

A Academia foi mais do que um lugar. Académico foi e é o espírito, a disposição para adquirir e transmitir o conhecimento. Platão, sabemos por Aristóteles, aderira na juventude ao princípio heraclidiano 
de que todas as coisas sensíveis estão em perpétuo fluir de transformação e que, portanto, não podemos ter delas qualquer conhecimento. Não foi o desejo de resolver o enigma do Universo sensível que justificou a fundação da Academia, mas sim a necessidade da busca do saber, o exercício da episteme que esclarecesse a vida biológica, psíquica e social.

A Academia tinha o propósito de avançar na procura da sabedoria. Viveu da certeza socrática de que se os homens fossem libertados dos miasmas do preconceito e das falsas convicções veriam a verdade da vida. O seu processo educacional (educare é conduzir - duco, para fora $-e x$ ) foi o do desenvolvimento do ser humano em todas as suas potencialidades, foi o esclarecimento da Paidéia, da cultura pela educação constituída pelo legado de uma geração para a outra.

A Academia não pretendeu o saber funcional, mas a essência do saber como força dignificante da vida. Os dois sistemas educacionais que são a República e as Leis giram em torno das premissas filosóficas da crítica às potências educacionais do seu tempo, particularmente a sofística, a retórica e a religião. A Academia não se dedicou ao atual e efémero, mas ao ser, ao eterno (Platão, 1981). A "Teoria das Ideias" nada mais é do que a tentativa de desvendar o mistério de como objetos ideais do pensamento podem ser conhecidos. A resposta que dá é a da reminiscência, da anamnesis: podemos conhecer estes objetos pela reflexão, trazendo-os de novo à consciência. Os objetos ideais vêm do próprio intelecto, o conhecimento inconsciente, por um processo análogo ao que nos permite recordar algo que já conhecemos e que esquecemos.

Institucionalmente, a Academia não foi de modo algum um grupo em que um era o sábio e os outros se encontravam à procura das doutrinas ou dos serviços do mestre, mas uma comunidade de estudiosos com diferentes graus de desenvolvimento (Jaeger, 1979). As interpretações da "Sétima Carta" de Patão - escrita já em idade avançada, contra a podridão moral do "Estado do Governo dos Trinta" - 
não deixam dúvidas que ele, como a sua Academia, tinha o propósito de busca do conhecimento verdadeiro, do saber fundado, não do adestramento sofístico da conveniência.

Nos nove séculos que durou (387a.C. - 529 d.C.) a Academia muitas vezes deixou de observar este ideal. Depois da morte de Platão, a Academia Antiga (387-316 a.C.) dedicou-se ainda aos problemas sobre o homem e a existência, decaindo no final para a matematização pitagórica. Foi rendida pela Média Academia (316-241 a.C.), que também estudou a questão do conhecimento, mas que, impossibilitada logicamente de excluir a experiência sensível do saber, declinou, torando-se equívoca e probabilística. A Nova Academia (160 a.C. - 84 a.C. e, desfigurada, até 529), a de vida mais longa, que a substituiu, restaurou o dogmatismo, atribuindo valor gnosiológico à evidência. Ante a impossibilidade de fundamentar por evidência a ética, tornou-se, na sua decrepitude, eclética ao absorver o pitagorismo da Antiga e o probabilismo da Média academias. Ao cabo, foi sincrética, juntando a tudo isto o estoicismo e o peripatetismo que conformam a obscura amálgama de neoplatonismos (Cornford, 1952).

Este pequeno resumo dos zénites e nadires do ideal académico nos serve para precisar que o termo "fraude académica" não se refere aos ilícitos praticados contra uma organização ou grupo de organizações abstratas, mas ao ato de fraudar o ideal académico, expresso na episteme, na busca intencional e sistemática do conhecimento mediante a reflexão, a fundamentação, o diálogo e o convívio intelectual.

\subsection{Os indutores}

Até aqui expus uma visão razoável da ética no mundo contemporâneo, descrevi as fraudes e o contexto em que ocorrem e detalhei o quadro de referência moral que as circunscreve e as dicotomias 
que as explicam. Passo agora a examinar os possíveis indutores das fraudes académicas discentes e da forma de confrontá-las.

A fraude pode ser confrontada de muitas maneiras. As mais eficientes são aquelas que as inibem no nascedouro, mediante a supressão ou, ao menos, a atenuação dos seus indutores. Em um livro que presume a intenção de esgotar o assunto, o jurista Joseph Wells aponta como indutores da fraude as pressões psíquicas, económicas e sociais, a oportunidade e a racionalização no marco da cultura em que o ato de fraudar é praticado e julgado (Wells, 1997). Examinarei estes móbeis na forma que se apresentam face às dicotomias morais liberdade-condicionamento, individualização-equalização e racionalização-paradigma.

\subsubsection{A liberdade condicionada}

Talvez a maior contribuição de Michel Foucault para o entendimento do mundo contemporâneo tenha sido o esclarecimento de que a opressão que pesa sobre a sociedade não deriva exclusivamente dos sistemas de dominação instituídos — os governos, as igrejas, as corporações, etc. - mas de instâncias teoricamente insuspeitas, como a psiquiatria, a filosofia, as instituições, inclusive a académica. Em todas e em cada uma destas instâncias existem manifestos ou não, instituídos ou dissimulados, dispositivos - do poder, mas também do saber e da subjetividade - limitantes ou supressores da liberdade (Deleuze, 1990).

Desde meados do século $\mathrm{xx}$, principalmente a partir da obra de Arendt A condição bumana, sobre as condicionantes da cultura ocidental, que a questão da liberdade se equaciona pela busca e determinação do estatuto de pessoas e grupos com relação à sua origem, à sua situação social, profissional, económica, e assim por diante. Reduzida ao tema de que nos ocupamos, a questão da liberdade leva 
a inquirir em que medida a fraude discente resulta de uma opção livre e consciente ou de um ato condicionado pelos dispositivos sociais, de que o mais das vezes não se tem consciência.

Esta linha de indagação conduz a outra antiga querela filosófica: a que contrapõe a determinação natural à determinação cultural do agir humano. A oposição, estabelecida por Kant, entre a liberdade de escolha e a natureza constitutiva do instinto normal da espécie. A "natureza humana" abarca tudo o que é inato e espontâneo na humanidade, incluindo o que é próprio e superior à animalidade. Alia os instintos primários, comparáveis à função fisiológica, que resultam diretamente da estrutura primitiva do ser vivo e do automatismo adquirido que se tornou inconsciente. A fraude, neste caso, seria uma inclinação de uma existência que se determina a si própria, sem interveniência de uma causa externa.

Mas esta possibilidade de justificativa moral não se sustenta. O instinto, como queria Bergson (1986) se opõe à inteligência, ao propósito, à escolha que caracteriza a fraude. Atribuir a fraude à natureza humana seria afirmar o que não faz sentido, a saber: que a transgressão ética corresponde ou a tudo que é dependente da vontade - como diz Rousseau (1973): "tal é este puro movimento da natureza, anterior a toda reflexão" - ou à corrupção do natural, inato e espontâneo. Se fosse instintiva, a fraude seria a norma. Escaparia à ética e deveríamos entendê-la no marco improvável de uma etologia humana. O que poderia ser explicado pela natureza instintiva do ser humano seria a evasão do constrangimento desmesurado do meio em que vive. Um constrangimento que levasse à excitação dos desejos e à anulação das vontades individuais

Outra possibilidade é aquela em que Bernard de Mandeville (16701733), em sua Fábula das abelhas: vícios privados, beneficios públicos (1997), defendeu a dolorosa tese de que a sociedade vive em fraude, luxúria e orgulho, e de que a única forma de superar a má índole social é a de que cada indivíduo cuide apenas do seu interesse 
próprio. O esforço para ser bom e virtuoso colocaria o homem em oposição ao interesse geral e conduziria à destruição da sociedade. Adam Smith acolheu a tese de Mandeville para os bens económicos e a repeliu para os bens espirituais.

No seu rastro de Mandeville e de Smith, o liberalismo económico prega que o motor da moralidade é o altruísmo e a temperança e que o motor do progresso é o egoísmo e a cobiça. Não nota, ou finge não notar a improbabilidade da coexistência entre estas duas lógicas. Uma contradição que está na raiz da moralidade duvidosa dos que advogam a legitimação da fraude pelo imperativo de se atingir metas e índices. A instituição académica do Ocidente, originalmente emaranhada na vã tentativa de conciliar a liberdade da razão com a fé cristã, ganhou traços esquizofrénicos ao resvalar no propósito de fazer convergir o progresso do conhecimento e o utilitarismo económico. Instituiu aferidores materiais na tentativa de medir o avanço do conhecimento "útil". Decaiu ao produtivismo, a velhacaria mais tirânica do aparelho académico, que, sob o pretexto da contenção do ilícito científico, instituiu as publicações e citações como utensílio genérico de regulação, uma maquinação só comparável àquela gerida pela Igreja medieval. A regra que determina o que é ciência e quem a faz não tem o objetivo de ampliar o conhecimento, mas de preservar a quimera da mensurabilidade. Carregado da toxina botulínica, o sistema obtuso, que pretende medir o que por definição é incomensurável, vem degradando a alma da instituição académica. Bifronte como Janus, a academia no Ocidente dá-se ares. Repudia o denso e duradouro, interdita a descoberta, atem-se ao fait-divers e sufoca a inovação. Desconhece que a pior tirania não é aquela que interdita, mas a que obriga.

À dissociação entre pensamento e ação, entre a liberdade de conduta e a sua contenção pode ser atribuída parte do condicionamento que os dispositivos sociais impõem sobre os discentes. A instrumentalização mutilante da episteme anula esperanças e cria necessidades 
buropáticas. Legitima a fraude como instrumento emancipatório. O dístico "necessitas legem no habet", a esplêndida sabedoria da língua que herdamos e empobrecemos, permite duas interpretações: "a necessidade não reconhece nenhuma lei" e "a necessidade cria a sua própria lei”. Pressionados pela necessidade de sobreviver, de submeter-se à instituição que tudo regula e restringe, o discente tende instintivamente a fazer uso dos expedientes de que dispõe, ainda que de aqueles menos sustentáveis moralmente. Coloca a questão de perguntar em que medida as fraudes de reprodução e de pilhagem não seriam uma via de passagem, um meio de sair, de escapar de um mundo contraditório, hostil e injusto.

\subsubsection{A individualização equalizada}

Em pleno século das Luzes, o filósofo da educação Claude-Adrien Helvétius (Paris, 1715-1771), viu sua obra Do bomem, das faculdades intelectuais e de sua educação (Cumming, 2000) ser queimada por ordem da Sorbonne, da libertária Sorbonne. As alegações foram outras, mas quer me parecer que a instituição não pode suportar a verdade da assertiva de Helvétius que inspirará o Candide de Rousseau: ensinamos às crianças a moral que ninguém cumpre e que o adulto deve desaprender para sobreviver na nossa sociedade.

Sem poder se desembaraçar desta incongruência, o meio académico é estruturalmente controlador e avesso às exceções e aos excessos. O cômputo dos atores, dos discentes, docentes e administrativos, que alcança muitas vezes a casa das dezenas de milhares de pessoas envolvidas, e as demandas internacionais de padronização, que obedecem a critérios estranhos às culturas locais, parece não deixarem alternativa à equalização rasa de governança e procedimentos. Uma uniformidade que se contrapõe diretamente à episteme. Pior: que contradita o zeitgeist, o espírito do tempo. 
A sociedade que podemos considerar como sendo a nossa é a de uma classe média universalizada pós-pequeno burguesa que, simultaneamente, exalta e restringe a autarkeia. Uma sociedade que reverencia o empreendedorismo e censura o risco económico. A conquista da autonomia no cômputo da moral vigente é, para dizer o mínimo, espinhosa. Uma realidade comum a ideologias e regimes. O caminho que a minha geração acreditou ser emancipador, como o do festejado e ambíguo Che ("Hay que endurecerse, pero sin perder la ternura jamás."), terminou na idealização de um personagem que tirou a vida de dezenas de inimigos políticos. Ternamente. As iniciativas estudantis de 1968 na França, nos EUA e depois em todo o mundo que supusemos revolucionárias, desaguaram em meras reformas. Incitaram uma contrarreforma marcada pelo tolhimento do novo, pelo normativismo equivalente ao daquela outra, a inquisitorial. Sua mais clara expressão frauda a mais comezinha moral académica: é a escravização de estudantes, que devem pesquisar e redigir textos perfilhados pelos professores. As demais expressões do normativismo: currículos sedimentados, estruturas obsoletas, interdição da expressão individualizada instigam os discentes ao descompromisso com os processos e com os produtos da sua trajetória académica. A equalização normalizou a impudicícia. Enjeitados, desencantados, é possível que os discentes fraudem por desesperança de quem antecipa a partida.

Não por acaso uma fração considerável dos empresários de maior êxito na nossa época, dentre eles os icónicos Steve Jobs (falecido em outubro de 2011) e Mark Zuckeberg, não terminou a universidade (Issac, 2011; Rampell, 2013). A eventual imoralidade da fraude académica diz pouco aos estudantes deste nosso tempo que copertencem à cultura dos emancipados da titulação universitária, do Facebook, do Twiter, do LInkedIn. Culminâncias tecnológicas que irão desaparecer, mas que já mudaram a vida psíquica e social. As grandes universidades tentam se tornar "virais" com seus 
cursos online. Abraçam a superficialidade inutilmente porque não têm como atingir pessoas sem identidade profissional definida e que já sempre caminham à sua frente. Pessoas que investem seu tempo, seus recursos e sua vida, em startups, em redes sociais, em samarthphones, em tablets. Pessoas em permanente comunicação digital, pessoas que criam novos negócios, financiam-se por crowdfunding, comem produtos paleo. A imoralidade da fraude diz pouco também aos estudantes que pertencem à cultura dos indignados, dos manifestantes, dos occupy, ou como quer que se denominem aqueles que protestem sem um conteúdo determinado de reivindicação. Que pertencem à geração dos sem projetos, dos incodificáveis, dos irrotuláveis, dos que sentem (quase escrevi "dos que sabem") que o que aí está - normas, instituições, ideologias - está vencido, perdeu a validade.

Existe a possibilidade de que o descompromisso moral seja uma reação não só ao arcaísmo institucional, mas também à economia consumista, ao imediatismo do prazer, à subordinação ao útil e ao instrumental que vêm num crescendo alucinante desde meados do século passado. No entanto, pesando opiniões e expectativas, não restam dúvidas quanto ao divórcio entre o instituído e o vivido pelos discentes. Se tudo o que percebemos e declaramos é biograficamente determinado, se não podemos nos exilar do nosso tempo e da nossa história pessoal, cada pessoa supostamente organiza seu mundo segundo categorias de faculdade e estranhamento, de personalidade e sentimento, de intimidade e anonimato, de afastamento e de compromisso, seria de perguntar sobre em que medida o discente, fraudador ou não, imerso no espírito do seu tempo se sente comprometido com as instituições académicas. Decorre desta dúvida a questão de como reatar os laços de compromisso com um paradigma imposto, desbaratado tanto do espírito do tempo como do espírito da Academia. 


\subsubsection{A racionalização paradigmática}

Impor um paradigma é uma arbitrariedade. Estabelecer um paradigma académico é cometer o ato arbitrário de sustentar que o relevante é isto, e não aquilo, que a centralidade está nisto, e não em outra coisa. Impor um paradigma é desvalorizar o diferente. O paradigma é um exemplo, um modelo. O grego para-deigma, aquilo que se mostra ao lado, é a idealização que orienta o agir. É o exemplo a seguir, o exemplar eleito, seja uma pessoa, um grupo, uma ideia. O exemplo, lembra Agamben (2013: 18), é um caso particular do real, mas tomado como universal. O exemplo paradigmático é uma singularidade como outras, mas que não é definida por nenhuma propriedade particular. É protótipo que vale para todos os casos do mesmo género, o género em que se inclui como um mero caso dentre outros. Decorre daí que todo paradigma é falho. Algo que é e que não é ao mesmo tempo. Algo que parece genérico e atemporal, mas é particular e datado.

O paradigma positivista que aí está data do século xix. Eça de Queirós teve a ilusão de que estaria em vias de desaparecer:

\footnotetext{
"O positivismo científico considerou a imaginação como uma concubina comprometedora.... e fechou o homem em um laboratório a sós com a sua esposa clara e fria, a razão. O resultado foi que o homem começou a aborrecerse monumentalmente e a suspirar por aquela companheira tão alegre, tão inventiva, tão cheia de graça e de luminosos ímpetos... a esperança, quase a certeza... de que... ninguém mais com medo da ciência duvidará em correr aos braços da imaginação”. (Queirós, 1966)
}

Eça teve esta doce esperança em 1893. Uma esperança frustrada. O positivismo e a matematização de tudo continuam a assolar como forma paradigmática de razoabilidade. 
Desde o final do século xviII, o raciocínio matemático é um dos sustentáculos do pensamento ocidental. Nos tempos que correm tende a ser o único, fraudando o espírito académico. Traem a doutrina dos números de Platão, que está entre as àgrafa dógmata, as doutrinas não escritas, de que nos fala Aristóteles (1952), que colocou os entes matemáticos como pontos entre as ideias e o real sensível. Traem Hume, e praticamente todos os filósofos depois dele que negaram que o pensamento moral e o pensamento prático possam ser matematizados - "reason is and ought only to be the slave of the passions and can never pretend to any other office than to serve and obey them" - (Howson, 2000: 110). Traem Rousseau, que mostrou como e por que a vida só pode ser vivida de acordo com a natureza e com os afetos.

Ante esta violência contra o que deveria ser o espírito académico, não seria de se perguntar se parte das fraudes discentes não decorre do abandono forçado do que não pode ser numericamente demonstrado ou sequer discutido? Não seria o paradigma matematizante o grande indutor das fraudes de conteúdo, de produto e de generalização? Não seria de se perguntar se a tolerância com as fraudes nada mais é do que uma resposta evasiva da academia que tarda em abdicar deste paradigma?

\subsection{Tolerância}

A ilusão dos metafísicos, escreveu Nietzsche (2010), reside na sua crença na oposição dos valores. Os valores não se opõem na forma que creem os maniqueus. À coragem se opõe a covardia, mas também a temeridade. À fraude se opõe a franqueza, mas também o conformismo. Os valores morais, como quaisquer valores (Nietzsche, 1990), são criações históricas, conveniências sociais, heranças aprendidas. Sua hierarquia muda com o tempo e com a 
circunstância. Se e quando tolerada, a fraude académica discente o é por razões históricas, contextuais, presentes.

Tolerar - ensina a raiz latina tollo - denota o esforço que fazemos sobre nós mesmos. Ninguém tolera o que é bom. Toleramos ou dizemos tolerar ou, ainda, pregamos que se tolere o que é mau, o que é ruim. Nos primórdios do pensamento ocidental, com Sto. Agostinho (1952), a tolerantia tem uma aceção coletiva: a do autocontrole da cristandade ao lidar com os maus, com as pessoas imorais, com os infiéis. A da caridade, que ajuda a suportar os que são um peso para a humanidade. A tolerância com a fraude académica discente, no entanto, parece se explicar de outra maneira: ela decorreria da prudência, da indulgência e da conveniência.

A vertente prudencial da tolerância deriva do direito canónico, que pela volta do primeiro milénio já sustentava que o mal não deve ser punido quando é secular, o que não significava aprová-lo (Ecclesia non approbat, sed permittit). Permitia-se o mal pela impossibilidade de eliminá-lo - como no caso da prostituição - ou em favor do ordenamento do convívio com grupos irredutíveis à lei canónica, como o dos judeus (Bjeczvy, 1995). O paralelo com a tolerância prudencial se aplica ao caso da fraude académica na medida em que a seguir-se todas as normas burocráticas, a se aferir tudo que é copiado na época do Google e da Wikipédia, a se discutir a fragilidade dos fundamentos e dos argumentos, e, principalmente, a se alardear a baldia tolice que distingue a maior parte da produção académica da atualidade, a instituição universitária se veria em sérias dificuldades.

A tolerância passou a significar a indulgência entre os credos após as guerras religiosas dos séculos XVI e xVII. Os argumentos a seu favor são de ordem moral, de ordem eidética, de ordem utilitária, de ordem legal, de ordem política e de ordem epistemológica. O argumento moral de Erasmo (1999) e de Locke (1964), diz que a perseguição é violência e que a violência se opõe à civilidade e à caridade. $\mathrm{O}$ argumento da essência diz que se concordamos política 
ou religiosamente no fundamental (credo minimum), a razão da intolerância desaparece. Voltaire (1829) argumentou que a tolerância se opõe ao fanatismo. Que era preciso esmagar o fanatismo cristão (écraser l'Infâme) fundado na superstição e na ignorância, em nome do interesse público. Dizia ele que devemos nos tolerar porque todos somos falíveis. O argumento legalista diz que a intolerância é um mal porque produz a coalizão dos dissidentes, e porque a repressão aos hereges é contraproducente porque cria mártires. O argumento político diz que a intolerância reforça a convicção dos que discordam e gera a revolta (Espinosa, 1982). O argumento epistemológico diz que devemos ser tolerantes porque ninguém pode pretender ter a razão absoluta, só Deus. Esta longa enumeração ensina que qualquer que seja o fundamento da tolerância indulgente com a fraude dos estudantes, ela tem uma raiz clara: a instituição e os docentes toleram porque são falíveis, porque não há uma das fraudes listadas no início deste texto que não seja praticada pela academia e pelos docentes. O número de artigos retirados, as contestações não respondidas às pesquisas, o dinheiro gasto com iniciativas sem justificativa, estão aí para quem quiser ver com isenção. Criou-se até uma figura estranha, a despublicação (sic), uma tentativa de manter a aparência de seriedade científica, procedimento em que a ênfase recai nos termos "tentativa" e "aparência".

A terceira vertente explicativa da tolerância com a fraude académica discente é coeva. Herbert Marcuse (1970) sustentou que a tolerância com os dissidentes na sociedade liberal tem o propósito de servir não para a emancipação dos grupos e das pessoas explorados, mas para adormecer os impulsos libertários. Com isso, torna-se repressiva, embora sob a aparência de libertadora. Marcuse, que informou intelectualmente os movimentos rebeldes da segunda metade do século passado, trouxe à luz a ideia de que a autodeterminação é viciada pelas instituições. De que a ideologia da tolerância favorece a conservação do status quo arcaico. Uma ideia que leva a perguntar 
se a tolerância com a fraude entre os universitários não seria uma estratégia conservadora.

\subsection{Discussão}

As categorias e os argumentos que expus postulam a fraude discente como consequência de um duplo desajuste: entre a universidade e o ideal académico, entre a instituição e o mundo que a circunda. Parece-me que a universidade de há muito abandonou a figura platónica da Academia. Buscou o anedótico e o burocrático. Ao renunciar ao ideal da profundidade e da propagação, a universidade se fez barroca. Parou no tempo e transformou-se em sua própria caricatura. O fenómeno da fraude pode não ser inteiramente negativo. A sua problematização abre a oportunidade de a academia meditar seu destino, justificar-se ante o mundo, exumar seu espírito.

Um eventual esforço de regeneração do ideal académico não se dará sem perdas de energia, de comodidades e de status. Mas não vejo outra forma de desencorajar a fraude universitária discente que não seja a recuperação do espírito platónico. Não cabe propor que a academia retroaja à Academia. É tolo tentar adequar o mundo às instituições. Mas não é tolo aspirar que a academia volte a viver para suprir a dificuldade de todos e de cada um em descobrir a verdade por si mesmo.

Fraudar o arbitrariamente estabelecido, mesmo quando expressão de uma inevitabilidade ou opção discordante, não pode deixar de produzir efeitos, de ter resposta. Mas esta resposta, não deve ser um revide. A resposta coercitiva pode ter base legal, mas não tem, necessariamente, fundamento na ética, e com certeza é estéril. Reprimir e castigar o fraudador não me parece justo ou produtivo. Há que considerar que a fraude não pode ser atribuível exclusivamente àquele que frauda e que a punição contém e dissimula, mas nada cria ou transforma. 
A explicação dada por São Tomás de Aquino (2006) para a punição infligida às crianças não batizadas é que se trata de um castigo que não é aflitivo, mas privativo: o da perpétua privação da presença de Deus. No meio académico, a punição límbica é imposta àqueles que por malícia, instinto, descaso ou ingenuidade fraudam o paradigma estabelecido pelas divindades universitárias. Condenados ao Limbo do olvido, do insulamento e da exclusão, os fraudadores recebem o castigo privativo do convívio, do acesso e da certificação. Um castigo fadado à banalidade formalista. Para os jovens do nosso tempo a privação académica não é desagradável. É fora da academia que a vida está acontecendo. Depois, está-se em boa companhia. Como no Limbo, está-se com os incontaminados, com aqueles que São Tomás falhou em justificar porque deveriam ser punidos.

\subsection{Referências bibliográficas}

Agamben, G. (2013), A comunidade que vem. Belo Horizonte: Autêntica. Aristóteles (1952), The works of Aristotle. Chicago: William Benton.

Bergson, H. (1986), L'évolution créatrice. Paris: Presses Universitaires de France.

Bjeczvy, I. (1995), “Tolerantia”, a medieval concept. Journal of the History of Ideas, 58( 3), julho.

Cornford, F. M. (1952), Principiun sapientiae: the origins of Greek philosophical thought. Cambridge: Cambridge University Press.

Cumming, I. (2000), Helvetius: His life and place in the history of educational thought. Londres: Routledge.

Deleuze, G. (1990), Michel Foucault, filósofo. Barcelona: Gedisa.

Erasmo, D. (1999), Lettre à Carondelet ( 5 de janeiro de 1523). In Julie Saada-Gendron, La tolérance. Paris: Flammarion.

Espinosa, B. (1982), Ética. Madrid: Aguilar.

Howson, C. (2000), Hume's problem: induction and the justification of belief. Oxford: University of Oxford Press. 
Isaac, C. (2011), Forbes 400: The Self-Made Billionaire Entrepreneurs Who Said No To College. Forbes / Leadership. Obtido em 19 de março de 2014 em http:// www.forbes.com/sites/worldviews/2011/09/23/forbes-400-the-self-made-billionaire-entrepreneurs-who-said-no-to-college/

Jaeger, W. (1979), Paideia: a formação do homem grego. São Paulo: Livraria Martins Fontes Ltda.

Locke, J. (1964), Carta a respeito da tolerância. São Paulo: IBRASA.

Mandeville, B. de (1997), The fable of bees and other writings. Indiana: Hackett Publishing Company, Inc.

Marcuse, H. (1970), Tolerância repressiva. In Robert Paul Wolff; Barrington Moore Jr. e Herbert Marcuse, Critica da tolerância pura. Rio de Janeiro: Zahar.

Mills, D. G. (2003), Lying/Perjury vs. Fraud/Deceit - Dissident Voice. Obtido em 12 de março de 2014 em http://www.dissidentvoice.org/Articles7/Mills_BushFraud-Deceit.htm

Nietzsche, F. (1990), A genealogia da moral. Lisboa: Guimarães Editores.

Nietzsche, F. (2010), Além do bem e do mal. São Paulo: Centauro.

Platão (1981), Obras completas. Preâmbulos e notas por María Araujo, Francisco García Yague, Luis Gil, José Antonio Minguez, María Rico, Antonio Rodríguez Huescar e Francisco de P. Samarach. Introdução a Platão por José Antonio Miguez. Madrid: Aguilar.

Queirós, E. [1893], (1966), Positivismo e idealismo. Notas contemporâneas - Obras completas. Porto: Lello e Irmão.

Rampell, C. (2013), America's Biggest Entrepreneurs: High School Dropouts. Economix. Obtido em 19 de março de 2014 em http://economix.blogs.nytimes. com/2013/04/19/americas-biggest-entrepreneurs-high-school-dropouts/?_r=0

Rousseau, J. J. (1973), Discours sur l'origine et les fondements de l'inégalité parmi les hommes. Paris: Aubier Montaigne.

Santo Agostinho (1952), On Christian doctrine. Chicago: Enciclopaedia Britannica, Inc. São Tomás de Aquino (2006), Suma teológica: os sacramentos. São Paulo: Loyola, vol. 9. Sokal, A. D. (1996), Transgressing the Boundaries: Towards a Transformative Hermeneutics of Quantum Gravity. Social Text, 46/47 (primaver/verão). Duke University Press, pp. 217-252. 
Voltaire, F. M. A. (1829), Oeuvres complètes de Voltaire (com notas, prefácio, advertências, observações históricas e literárias. Paris: Armand-Aubree, Éditeur.

Wells, J. T. (1997), Occupational fraud and abuse. Londres: Obsidian Publishing Co. 